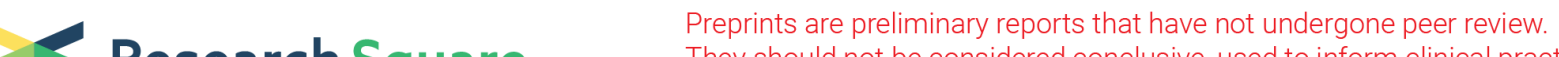 Research Square They should not be considered conclusive, used to inform clinical practice, or referenced by the media as validated information.
}

\section{Uncertainty Analysis of Optimal Instruction for WDN Pipes Repair and Replacement Using Fuzzy Cut - Hydraulic Simulation Approach}

\section{S.M. Jafari}

GUASNAR: Gorgan University of Agricultural Sciences and Natural Resources

\author{
A.R. Zahiri \\ GUASNAR: Gorgan University of Agricultural Sciences and Natural Resources \\ O. Bozorg Hadad \\ University of Tehran \\ Mahmoud Mohammad Rezapour Tabari ( $D$ mrtabari57@gmail.com ) \\ University of Mazandaran https://orcid.org/0000-0002-4837-5026
}

\section{Research Article}

Keywords: Uncertainty analyses, Fuzzy, Hydraulic simulation, Pipe repair and replacement, WDN, Reliability.

Posted Date: February 21st, 2022

DOI: https://doi.org/10.21203/rs.3.rs-1341370/v1

License: (a) (1) This work is licensed under a Creative Commons Attribution 4.0 International License. Read Full License 


\section{Abstract}

Optimization of the initial design or pipes repair and replacement instructions of water distribution network (WDN) during operation period is based on the crisp values. Some input variables such as node demand, pipe roughness coefficient and reservoir water level have the uncertain nature. Changing the input parameters values during operation period, due to uncertainty, changes the water distribution network behavior and performance compared to the crisp input parameters values. Recognition and analyzing these behaviors are very important to make the right decision to deal with their consequences and reduce the water distribution network problems. In this research, the WDN nodes pressure uncertainty due to the pipe's roughness coefficient and the nodes demand uncertainty as input parameters, is analyzed after the implementation of the optimal pipes repair and replacement instruction. For the purpose, a combination of simulation model (EPANET) and fuzzy a-cut approach is used. Fuzzy membership functions (MF) of the input and output variables are selected as triangular type. The extreme values combinations of two uncertain input variables, at each uncertainty level, in the form of four scenarios, were considered as the input fuzzy set of the simulation model. Between the research scenarios, the second scenario, which is the combination of the minimum pipe roughness coefficient and the maximum demand, is known as the critical scenario. The results show that in the critical scenario, at the highest uncertainty level, the WDN reliability index is very low and about 30 to $40 \%$ due to lack of required pressure of the most nodes. At the uncertainty lower levels, the reliability index rises above $75 \%$, which is relatively acceptable. In the first and fourth scenarios, the network reliability index is always more than $72 \%$. In the third scenario, the network reliability index, at all uncertainty levels, is always more than $90 \%$.

\section{Introduction}

Pipes in the WDN need to be replaced and repaired during the operation because of pipes aging, deterioration, failure and the necessity for WDN development. Selecting the most appropriate pipes for replacing or repairing and replacing diameter are important challenges for the WDNs operational management because they affect the WDN's cost and hydraulic performance. The solution to the critical challenge is providing optimal pipes repair and replacement instructions using multi-objective optimization approaches, which various researchers have studied (Baños et al. 2011; Shafiqul et al. 2014; Wang et al. 2015; Liu et al. 2017; Bozorg-Haddad et al. 2017; Dini and Tabesh 2018; Jafari 2020).

Optimization and hydraulic simulations of WDN to provide optimal instruction for pipes repair and replacement are always performed by simplified models of a real WDN based on the crisp and known values of input variables. Values of some input variables such as nodes demand, pipes roughness coefficient, pipe length and diameter and reservoir water surface level, etc., fluctuate during the operation period. These variables are called uncertain variables. Sources of the uncertainties are divided into three categories: 1) measurement tools, 2) lack of knowledge, and 3) network simplification. The first category includes the pipes length and diameter, the pumps specifications and the water surface level of the tanks (Ivetić 1996; Kapelan et. al. 2005). In the second and third categories, variables such as pipe roughness coefficient, pressure head loss, and nodes demand are noteworthy. Although measurement criteria may be wrong, using better measurement tools can prevent errors and mistakes of them. Therefore, the most uncertainties belong to the second and third categories, is lack of information about parameters and WDN simplification. 
Uncertain variables cause uncertainty in the WDN output parameters such as pipes velocity, flow rate, nodes pressure, and demand. Preparation of instructions for pipes replacement and repair and developing WDNs based on crisp values cause unpredictable behavior and change the hydraulic and physical performance during the operation period of WDNs. Therefore, it is necessary to study the hydraulic and physical behavior of the WDN in the uncertain conditions of the operation period.

Generally, studies on the effect of uncertainty on WDN behavior can be classified into two categories: uncertain design and uncertainty analysis of WDN. In the first category, uncertain values of variables are entered into the network optimization process, then WDN specifications are calculated (Shibu and Reddy 2012; Farmani et al. 2005a, 2005b; Donger and Gupta 2017; Moosavian and Lence 2018). In the second category, which is the subject of this research, the hydraulic and physical performance of the network under uncertain scenarios are predicted and identified. It makes it possible to provide the necessary arrangements for the operator to face possible consequences and problems. Therefore, uncertainty analysis of WDN is essential, especially in the cases of WDN pipes replacing or repairing and development.

Various researchers have developed different methods for uncertainty analysis of the WDNs. First-order second momentum (FOSM) is an uncertainty analysis method that estimates uncertain output values based on the Taylor series. This method has low accuracy for estimating the output values of nonlinear problems because it approximates based on the first-order approximation of the shortened Taylor series. Therefore, researchers have rarely used it in problems related to the WDN (Tolson et al. 2004; Hwang et al. 2017). The Monte Carlo simulation (MCS) approach is one of the most well-known methods widely used by researchers for analyzing the uncertainty of water systems (Seifollahi-Aghmiuni et al. 2013; Hwang et al. 2017). In this method, it is necessary to specify the probabilistic distribution function (PDF) for the uncertain variables. The studies show that in this method, the run time is high, especially in a real WDN, and choosing a proper PDF is very effective in the accuracy of the results.

Fuzzy theory approach is a powerful tool for uncertainty analyzing of nonlinear problems in the absence of uncertain variables information. Therefore, in the last decade, various researchers have widely used it to analyze the uncertainty of the urban WDNs design (Shibu and Reddy 2011; Haghighi and Zahedi Asl 2014; Sabzkouhi and Haghighi 2016; Moosavian and Lence 2018; Geranmehr et al. 2019). Shibu and Reddy (2011) developed a Fuzzy - Cross entropy model for uncertainty analysis of WDN design. They considered pipes roughness coefficient as uncertain variable. In this model, the fuzzy theory was used to quantify the uncertainty of the pipe roughness coefficient, and the entropy method was used to optimize the fuzzy MF. They stated that the proposed approach could effectively handle the uncertainty of the WDN with low calculation volume. Haghighi and Zahedi Asl (2014), and Sabzkouhi and Haghighi (2016) used a combination of fuzzy theory and multi-objective optimization methods to uncertainty analysis of the WDN design. In their studies the NSGA-II and MO-PSO optimization algorithm is used for determining the maximum and minimum values of uncertain variables in each fuzzy-cut. They stated that NSGA-II and MO-PSO optimization algorithms had a significant role in solving the problem and improved the computational efficiency of the WDN uncertainty analysis. Moosavian and Lence (2018) developed a fuzzy-analytical approach based fuzzy theory for uncertainty analysis of WDN design. They showed that if there is only one uncertain variable, only two hydraulic simulations are performed to determine the extreme values of the uncertain variable, and the number of hydraulic simulations doubles for each node increase. Therefore, the proposed approach accelerates the 
uncertainty analysis of WDNs. Following the previous researches, Geranmehr et al. (2019) investigated uncertainty analyses of WDNs design with three uncertain variables include nodal demand, reservoir head, and pipe roughness coefficient. They developed a new approach based on type-2 fuzzy logic and parallel genetic programming to uncertainty analysis. Their research showed that the uncertainty of input variables has a high impact on flow velocity and thus significantly affects network performance.

Generally, the research results on using fuzzy methods in network design uncertainty analysis show that the fuzzy approach reduces the calculation volume and thus the speed of computations significantly and handles uncertainties effectively.

Uncertainty analysis of optimal instructions for repair and replacement of WDN pipes is essential due to the need to predict network behavior during operation and prevent problems due to changes in demand for nodes and the roughness of pipes. A review of previous studies shows that uncertainty analysis of WDN was only related to the network design stage. Therefore, researchers have not considered the uncertainty analysis of the optimal instructions for pipe repairing and replacing in WDNs.

In this research a new approach to fuzzy uncertainty analysis of the optimal instructions for pipes replacing and repairing in WDNs is developed. Nodal demand and pipe roughness coefficient are considered as the uncertain variables of the study. The proposed approach is used for uncertainty analysis of the optimal instruction of pipes replacing and repairing in a real WDN, presented by Jafari (2020). The innovations of this research are:

- Uncertainty analysis of optimal instructions for replacement and repair of WDN pipes Using a combination of fuzzy $\alpha$-cut method and EPANET simulation model

- Reduce the calculations volume and run time to analyze uncertainty of optimal instructions for replacement and repair

\section{Research Method}

\subsection{Uncertainty Analysis Approach}

Uncertainty analysis approach of the research is defined as a combination of fuzzy and hydraulic simulations models. The nodes pressure during the project planning period was considered as the uncertain output variable. The uncertainty analysis structure of this research is shown in Fig. 1.

\subsection{Case study}

The case study is the city of Gorgan that located in the north of Iran. Statistics of the Gorgan WDN pipe failure show that the number of pipe failures in WDN is relatively high due to the aging and deterioration of pipes, which has caused several operational problems. Therefore, the repair and replacement of WDN pipes are necessary (Jafari et al. 2020, 2021). Data required for this study are obtained from the Jafari et al. (2020, 2021).

\subsection{Optimal pipes repair and replacement instruction}


Jafari et al. (2020) presented the optimal instruction for replacing and repairing pipes of the Gorgan WDN. They developed a new optimization approach for preparing this optimal instruction. The proposed approach is a combination of WDN hydraulic simulation models (EPANET), hybrid model to predict the pipes failure rate (Jafari et al. 2020), multi-objective optimization model, and multi-decision-making model for select the best optimal solution. In the above study, the crisp values of annual nodes demand, during the project planning period, were predicted using the relationship presented by Taebi and Chamani (2005) and based on the nodes demand of in the base year and the geometric population growth rate. The pipes roughness coefficient of WDN during the project planning period was estimated using the relationship provided by Sharp and Walski (1988). Pipe failure rates were used to calculate the pipes repair cost in the optimization process. In the multi-objective model, the WDN's pipes diameter and the operation type (repair or replacement) in the planning period have considered as decision variables. Objective functions include minimizing the pipes repair and replacement cost and maximizing the WDN hydraulic performance. The mathematical form of the optimization model is as Eq. (1).

$$
\text { Satisfy : (Min(Cost), } \left.\operatorname{Max}\left(\operatorname{Re}_{\text {sys }}\right)\right)
$$

1

where, Cost is the total cost of pipes repair and replacement in the planning period (Rials) and $\mathrm{Re}_{\text {sys }}$ is the performance index of the WDN during the planning period.

The reliability index $\left(\mathrm{Re}_{\text {sys }}\right)$ is as the Eq. (2).

$$
\operatorname{Re}_{\text {sys }}=\left(\mathrm{WSI}_{\mathrm{sys}} \times \mathrm{MEI}_{\mathrm{sys}}\right)^{1 / 2}
$$

2

where, $\mathrm{Re}_{\text {sys }}$ is the total system reliability index, $\mathrm{WSI}_{\text {sys }}$ is the total system water supply index and $M E I_{\text {sys }}$ is the modified delivery uniformity index.

The NSGA-II algorithm has used to solve the WDN's multi-objective optimization problem. Selected optimal scenario provides the optimal pipes diameter and required operation type during the project planning period. An example of this instruction for pipes No.1 to 5 is presented in Table 2. 
Table 2

Example of the pipes optimal repair and replacement instruction

\begin{tabular}{|c|c|c|c|c|c|c|c|c|c|c|c|}
\hline \multirow{2}{*}{$\begin{array}{l}\text { No. of } \\
\text { pipe/Year }\end{array}$} & \multicolumn{5}{|c|}{ Type of operation } & \multicolumn{6}{|c|}{ Diameter (mm) } \\
\hline & 1 & 2 & 3 & 4 & 5 & Exist & 1 & 2 & 3 & 4 & 5 \\
\hline 1 & $\begin{array}{l}\mathrm{N}- \\
\text { replace }\end{array}$ & Repair & Repair & Repair & Repair & 150 & 250 & 250 & 250 & 250 & 250 \\
\hline 2 & Repair & Replace & Repair & Repair & Repair & 150 & 150 & 150 & 150 & 150 & 150 \\
\hline 3 & Repair & Replace & Repair & Repair & Repair & 150 & 150 & 250 & 250 & 250 & 250 \\
\hline 4 & Repair & Repair & Repair & Repair & Repair & 150 & 150 & 150 & 150 & 150 & 150 \\
\hline 5 & Repair & $\begin{array}{l}\mathrm{N}- \\
\text { replace }\end{array}$ & Repair & Repair & Repair & 150 & 150 & 150 & 150 & 150 & 150 \\
\hline
\end{tabular}

The proposed uncertainty analysis approach in the present study is applied to the optimal instruction of Gorgan's WDN pipes developed by Jafari et al. (2020).

\subsection{Fuzzification of uncertain input variables}

In uncertainty analysis of WDNs by fuzzy approach, it is necessary to define fuzzy MF or fuzzy set of uncertain input variables. The input fuzzy set can be formed based on measured or experimental data or a combination of these two data. In this study, uncertain variables include the nodes demand and the pipes roughness coefficient, whose MF are defined using measurement and recorded data.

2.4.1 Noes demand MF: In order to determine the fuzzy MF of the WDN's nodes, it is necessary to determine the definite nodes demand in each year of the planning period. In this research, the relationship presented by Taebi and Chamani (2005) was used (Eq. 4).

$$
\mathrm{Q}(\mathrm{t})=\mathrm{e}\left(\ln \left(\mathrm{Q}_{\mathrm{o}}\right)+\mathrm{K}_{\mathrm{g}} \cdot \mathrm{t}\right)
$$

\section{4}

where, $\mathrm{Q}(\mathrm{t})$ is the node demand in year $\mathrm{t}\left(\mathrm{m}^{3} / \mathrm{hr}\right), \mathrm{Q}_{\mathrm{o}}$ is the node demand in base year $\left(\mathrm{m}^{3} / \mathrm{hr}\right)$ and $K_{g}$ is the geometric population growth rate during period t year $\left(\mathrm{m}^{3} / \mathrm{hr} /\right.$ year $)$.

The WDN's nodes demand uncertainty can be quantified using trapezoidal or triangular MF (Donger and Gupta 2017). Previous research shows that the membership function suitable for nodal demand of WDNs is triangular (Donger and Gupta 2017; Geranmehr et al. 2019). The triangular membership function of the WDN's nodes demand is in the form of Eq. 5 (Geranmehr et al. 2019). 


$$
\mu\left(q_{i}\right)=\left\{\begin{array}{c}
o q_{i} \leq q_{i}^{\min } \\
\frac{q_{i}-q_{i}^{\min }}{q_{i}^{\text {crisp }}-q_{i}^{\text {min }}} q_{i}^{\text {min }} \leq q_{i} \leq q_{i}^{\text {crisp }} \\
\frac{q_{i}^{\max }-q_{i}}{q_{i}^{\max }-q_{i}^{\text {crisp }}} q_{i}^{\text {crisp }} \leq q_{i} \leq q_{i}^{\max } \\
o q_{i} \geq q_{i}^{\max }
\end{array}\right.
$$

where, $\mu\left(q_{i}\right)$ is the fuzzy membership function of node $\mathrm{i}, q_{i}^{\text {crisp }}$ is the crisp demand value of node $\mathrm{i}$ which equal to the annual demand value, $q_{i}^{\max }$ and $q_{i}^{\min }$ are maximum and minimum node demand, respectively.

The observed nodes demand data, in a 4-year statistical period, are used to determine the crisp, minimum, and maximum values of nodes demand of studied WDN (Eq. 5). Survey the observed nodes demand data shows that the minimum demand $\left(q_{i}^{\min }\right)$ and the maximum demand $\left(q_{i}^{\max }\right)$ of each node are respectively about $15 \%$ lower and $20 \%$ higher than the required demand or crisp demand $\left(q_{i}^{\text {crisp }}\right)$ of that node.

\subsubsection{MF of the pipe's roughness coefficient}

Roughness coefficient values of new pipes at the time of installation are equal to the values provided by the pipe factory. Pipe roughness coefficient in year $t$, after pipe installation, is calculated by Sharp and Walski (1988) (Eq. 6).

$$
C_{j}(t)=18-37.2 \log \left(\frac{e+t . a}{D_{j}}\right)
$$

6

where, $C_{j}(t)$ is the Heyzen -Williams's coefficient in year $t, D_{j}$ is pipe diameter $(\mathrm{mm}), j$ is pipe number index, $e$ pipe initial roughness high $(m), a$ is pipes roughness growth rate.

Due to the lack of access to the statistics of pipes roughness coefficient changes, the fuzzy membership function of the pipes roughness coefficient in this research is selected as triangular. (Sabzkouhi and Haghighi 2016; Moosavian and Lence 2018; Geranmehr et al. 2019). The triangular fuzzy MF of the pipe roughness coefficient determined by Eq. 7 (Geranmehr et al. 2019). 


$$
\mu\left(C_{j}\right)=\left\{\begin{array}{c}
o C_{j} \leq C_{j}^{\min } \\
\frac{C_{j}-C_{j}^{\min }}{C_{j}^{c r i s p}-C_{j}^{\text {min }}} C_{j}^{\text {min }} \leq C_{j} \leq C_{j}^{\text {crisp }} \\
\frac{C_{j}^{\max }-C_{j}}{C_{j}^{\max }-C_{j}^{\text {crisp }}} C_{j}^{\text {crisp }} \leq C_{j} \leq C_{j}^{\max } \\
o C_{j} \geq C_{j}^{\max }
\end{array}\right.
$$

where, $\mu\left(C_{j}\right)$ is roughness coefficient fuzzy MF of pipe j, $C_{j}^{c r i s p}$ is crisp roughness coefficient of pipe j which equals to design roughness coefficient, $C_{j}^{\max }$ and $C_{j}^{\min }$ are maximum and minimum pipe roughness coefficient, respectively. The crisp value of the roughness coefficient $\left(C_{j}^{c r i s p}\right)$ is calculated based on the pipe age by Eq. 6 .

\subsection{Fuzzification of uncertain output variable 2.5.1 Output variable selection}

In the fuzzy uncertainty analysis method, systems are divided into two categories, including 1) uniform and 2) non-uniform. In uniform systems, the change of the output variable relative to the input variables is uniform. Therefore, the input variables' extreme values lead to the output variables' extreme values (Branisavljevic and Ivetic 2006; Gupta and Bhave 2007). On the other hand, in non-uniform systems, the changes of the output variables relative to the input variables are non-uniform. The output values cannot be obtained using the limit values of the input variables. In these systems, optimization methods are necessary to determine the minimum and maximum values of output variables (Haghighi and Asl 2014; Sabzkouhi and Haghighi 2016).

In uncertainty analyses of WDN, selecting the appropriate output variable is very important because it represents network performance and determines the uniformity and non-uniformity of the WDN. Nodes available pressure and demand, pipes velocity, and flow rate are examples of WDN's output variables affected by input variables changes such as nodes demand, pipes roughness coefficient, and reservoirs water levels.

In Eq. 5 presented by Jafari et al. (2020), the WDN's reliability (Re) is a function of water supply $\left(\mathrm{WSI}_{\text {sys }}\right)$ and uniformity of water distribution ( $\mathrm{MEI}_{\text {sys }}$ ) indicators. Both indicators are a function of the required and supplied water (demand), resulting in the pressure of each node. Therefore, in the study, nodes pressure is selected as output variables.

\subsubsection{Fuzzy a-cut}


One of the helpful techniques to handle fuzzy uncertainty in complicated systems is the a-cut method. A fuzzy set that contains all values with membership function a $\in[0,1]$ is called the fuzzy a-cut of the MF (Abeb at al. 2000). In this method, different fuzzy a-cuts are first applied to the MF of the input uncertain variables. Then two minimum and maximum values of the uncertain variable are extracted in each fuzzy a-cut. Finally, for different combinations of minimum and maximum input variables, the values of the output variable are calculated, and its MF is obtained.

If the MF of a variable $A$ is normalized so that it changes between zero and one, the range changes of the variable A based on a-cut is expressed as Eq. 8 (Branisavljevic and Ivetic 2006).

$$
\left[A^{\text {crisp }}\left(\alpha+\frac{k_{1}}{1-k_{1}}\right)\left(1-k_{1}\right), A^{\text {crisp }}\left(\frac{k_{2}}{k_{2}-1}-\alpha\right)\left(k_{2}-1\right)\right]
$$

8

$$
k_{1}=\frac{A^{\text {min }}}{A^{\text {crisp }}}
$$

9

$$
k_{2}=\frac{A^{\max }}{A^{\text {crisp }}}
$$

10

where, $A^{\text {crisp }}, A^{\min }$ and $A^{\max }$ are crisp, minimum and maximum value of variable $\mathrm{A}$, respectively.

\subsubsection{MF of the output variable}

In determine the MF of the output variable, it is necessary to derive the extreme values of each input variables for different fuzzy a-cuts. In order to reduce the computational volume, only zero, $0.2,0.4,0.6$, and 0.8 fuzzy acuts are considered. Based on the Eq. 8, extreme values of uncertain variables in each a-cut are calculated using equations 11 to 14 . The values of $k_{1}$ for the node demand and the pipe roughness coefficient are 0.85 and 0.9 , respectively, and the values of $k_{2}$ for the node demand and the pipe roughness coefficient are 1.2 and 1.1 , respectively.

$$
q_{i}^{\min }(\alpha)=q_{i}^{c r i s p}(\alpha)[0.15 \alpha+0.85]
$$

11

$$
q_{i}^{\max }(\alpha)=q_{i}^{c r i s p}(\alpha)[1.2-0.2 \alpha]
$$

12

$$
C_{j}^{\min }(\alpha)=C_{j}^{c r i s p}(\alpha)[0.2 \alpha+0.8]
$$




$$
C_{j}^{\max }(\alpha)=C_{j}^{c r i s p}(\alpha)[1.1-0.1 \alpha]
$$

14

where, $q_{i}^{\min }(\alpha)$ and $q_{i}^{\max }(\alpha)$ are minimum and maximum demand values of node i for fuzzy a-cut respectively, $C_{j}^{\min }(\alpha)$ and $C_{j}^{\max }(\alpha)$ are minimum and maximum roughness coefficient values of pipe j, respectively.

Four uncertain scenarios are defined based on the combination of the extreme values of the uncertain input variables including nodes demand and the pipes roughness coefficient for each fuzzy a-cut (Table 3).

Table 3

Four uncertain scenarios used in each fuzzy a-cut

\begin{tabular}{|lllll|}
\hline $\begin{array}{l}\text { Scenario } \\
\text { name }\end{array}$ & $S 1$ & $S 2$ & $S 3$ & $S 4$ \\
\hline Characteristic & $C_{j}^{\min }(\alpha) \& q_{i}^{\min }(\alpha)$ & $C_{j}^{\min }(\alpha) \& q_{i}^{\max }(\alpha)$ & $C_{j}^{\text {max }}(\alpha) \& q_{i}^{\min }(\alpha)$ & $C_{j}^{\text {max }}(\alpha) \& q_{i}^{\max }(\alpha)$ \\
\hline
\end{tabular}

The values of the input variables in each scenario are used as the input of the simulation and optimization model to determine the values of the minimum and maximum output variables.

\subsection{WDN hydraulic simulation model}

In proposed approach, the hydraulic simulation of the studied WDN is required to calculate the pressure values of nodes in different uncertainty scenarios. EPANET can perform WDN hydraulic simulation in case of pressure change due to the WDN performance change, pipe failure and components leakage (Scholten et al. 2014). In addition, the possibility of establishing a connection between the EPANET program and the MATLAB programming environment is one of the program advantages to WDN simulation. Therefore, in this research, EPANET program is used as the WDN hydraulic simulation tool. In order to connect the EPANET program to the MATLAB program environment, a MATLAB code is developed, which allows to enter the required input information as well as call the hydraulic simulation results by accessing the EPANET program library.

\section{Results And Discussion}

\subsection{Fuzzy MF of uncertain input variables}

The node's demand and the pipe's roughness coefficient were considered as the uncertain input variables. The MF of these variables were determined based on Eq. 5 and Eq. 7. Due to the large number of the WDN's nodes and pipes, the MF of some nodes are presented as examples, in Figs. 2 to 5.

As shown in Fig. 2, the crisp demand value of node 54 in the first year is $3.367(\mathrm{I} / \mathrm{s})$, and the base range of the node's MF is between 2.86 and $4.04(\mathrm{l} / \mathrm{s})$. The crisp demand values of the node from the second to fifth years increase to $3.381,3.401,3.429$, and $3.463(\mathrm{l} / \mathrm{s})$, respectively, due to the increasing population covered by the node.

The pipe's roughness coefficient changes during the planning period are calculated using Eq. 6, which decreases with increasing the pipe's age. Therefore, the roughness coefficient of pipes increases with repair and 
decreases with the replacement of pipes. Figures 6 to 9 show the MF of some pipe's roughness coefficient as example. According to the optimal pipes' instructions, only repair operations are recommended on the pipe no.16 during the planning period (Jafari 2020). Therefore, the roughness coefficient of this pipe decreases during the planning period (Fig. 6). According to the optimal instruction, repair operations are recommended for pipe no. 60 from the first to third year. In the fourth and fifth year, replacement and repair operations are recommended for this pipe, respectively (Jafari 2020).

\subsection{Extreme values of uncertain input variables}

After determining the MF of the WDN uncertain input variables, it is necessary to extract their extreme values in five a-cut. The extreme values are used to calculate the nodes' pressure and obtain the MF of the nodes' pressure. Extreme values of the different fuzzy a-cuts related to the nodes demand and the pipes roughness coefficient provide in Tables 4 and 5 as the example.

Table 4

Extreme values of the demand node No.54 during planning period $(\mathrm{I} / \mathrm{s})$

\begin{tabular}{|lllllllllll|}
\hline \multirow{2}{*}{ - Cut } & Min. & \multicolumn{1}{c|}{ Max. } \\
\cline { 2 - 10 } & $\mathrm{Y}=\mathbf{1}$ & $\mathrm{Y}=\mathbf{2}$ & $\mathrm{Y}=\mathbf{3}$ & $\mathrm{Y}=\mathbf{4}$ & $\mathrm{Y}=\mathbf{5}$ & $\mathrm{Y}=\mathbf{1}$ & $\mathrm{Y}=\mathbf{2}$ & $\mathrm{Y}=\mathbf{3}$ & $\mathrm{Y}=\mathbf{4}$ & $\mathrm{Y}=\mathbf{5}$ \\
\hline 0 & 2.86 & 2.87 & 2.89 & 2.91 & 2.94 & 4.04 & 4.06 & 4.08 & 4.12 & 4.16 \\
\hline 0.2 & 2.96 & 2.98 & 2.99 & 3.02 & 3.05 & 3.91 & 3.92 & 3.95 & 3.98 & 4.02 \\
\hline 0.4 & 3.06 & 3.08 & 3.10 & 3.12 & 3.15 & 3.77 & 3.79 & 3.81 & 3.84 & 3.88 \\
\hline 0.6 & 3.17 & 3.18 & 3.20 & 3.22 & 3.26 & 3.64 & 3.65 & 3.67 & 3.70 & 3.74 \\
0.8 & 3.27 & 3.28 & 3.30 & 3.33 & 3.36 & 3.50 & 3.52 & 3.54 & 3.57 & 3.60 \\
\hline
\end{tabular}

Table 5

Roughness coefficient extreme values of the pipe No.60 during planning period

\begin{tabular}{|c|c|c|c|c|c|c|c|c|c|c|}
\hline \multirow[t]{2}{*}{$\alpha-C u t$} & \multicolumn{5}{|l|}{ Min. } & \multicolumn{5}{|l|}{ Max. } \\
\hline & $Y=1$ & $Y=2$ & $Y=3$ & $Y=4$ & $Y=5$ & $Y=1$ & $Y=2$ & $Y=3$ & $Y=4$ & $Y=5$ \\
\hline 0 & 70.83 & 69.90 & 69.30 & 103.37 & 100.01 & 97.39 & 96.11 & 94.91 & 142.14 & 137.52 \\
\hline 0.2 & 74.37 & 73.39 & 72.48 & 108.54 & 105.01 & 95.62 & 94.36 & 93.19 & 139.55 & 135.02 \\
\hline 0.4 & 77.91 & 76.89 & 75.93 & 113.71 & 110.01 & 93.85 & 92.62 & 91.46 & 136.97 & 135.52 \\
\hline 0.6 & 81.46 & 80.38 & 79.38 & 118.88 & 115.02 & 92.08 & 90.87 & 89.74 & 134.39 & 130.02 \\
\hline 0.8 & 85.00 & 83.88 & 82.83 & 124.05 & 120.02 & 90.31 & 89.12 & 88.01 & 131.80 & 127.52 \\
\hline
\end{tabular}

\subsection{Uncertain input scenarios}

By combining the extreme values of the input variables, four uncertain scenarios obtain for each fuzzy a-cut. These scenarios considered as the inputs of the studied WDN simulation model to determine the fuzzy MF of 
the output variable. As an example, the demand values of node No.54 and the roughness coefficient of pipe No.60 for the scenario S1 simulation are presented in Table 6.

Table 6

Demand values of node No.54 and roughness coefficient values of pipe No.60 in scenario S1

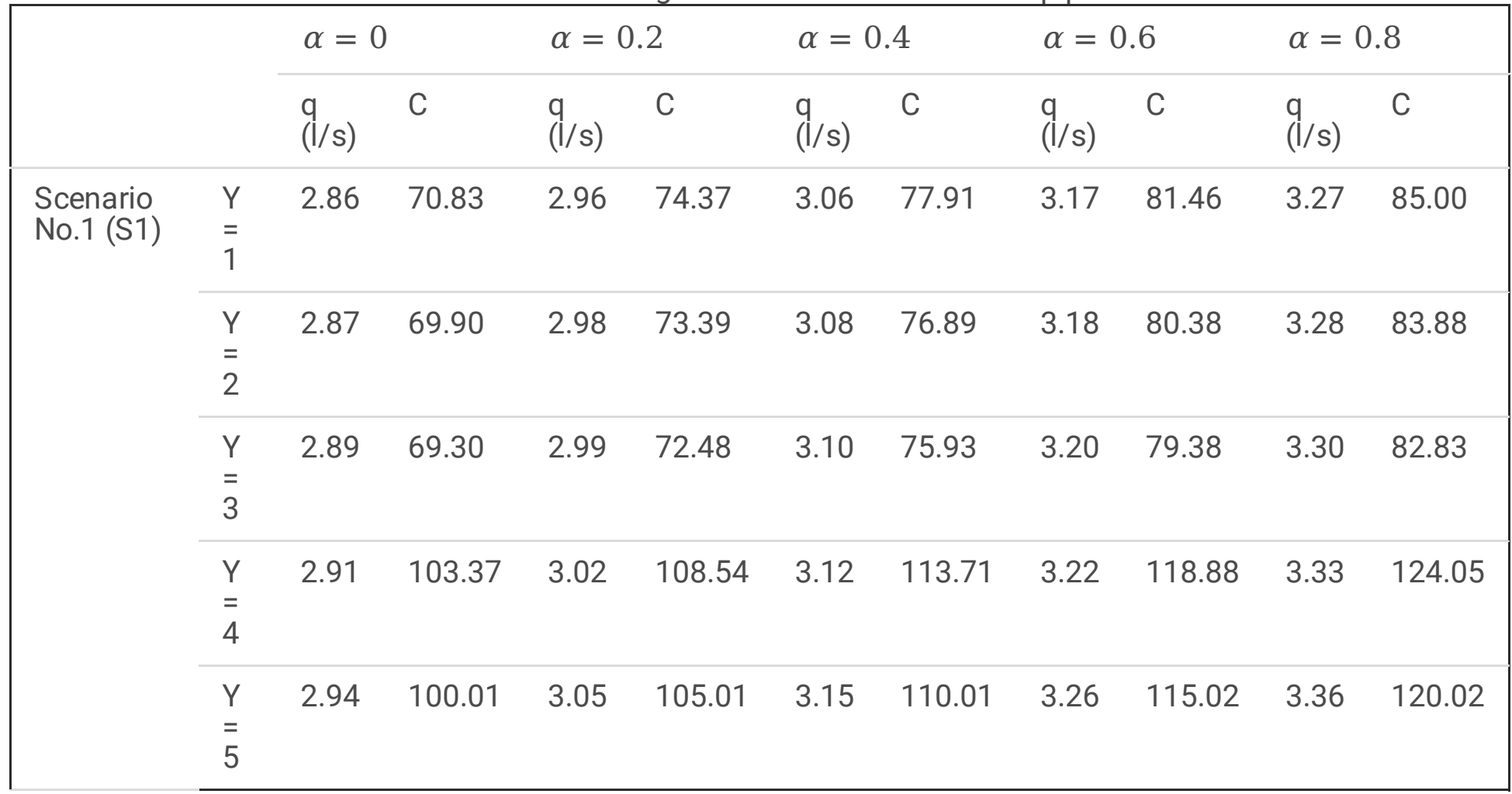

\subsection{MF of the uncertain output variable}

In WDNs, changes in node pressure are uniform versus changes in node demand and pipe roughness coefficient. Therefore, the extreme values of the network's input variables lead to the extreme values of network nodes' pressure. In this study, the limit values of nodes pressure are calculated using the EPANET hydraulic simulation model and the values of various uncertain scenarios, including the minimum and maximum demand of nodes and the roughness coefficient of pipes. These output values (nodes pressure) are used to obtain the MF of the nodes' pressure. For example, the pressure MF of nodes No. 104 and 63 during the planning period shown in Fig. 10 and Fig. 11.

As shown in Figs. 10 and 11, the MF of the nodes' pressure are triangles. It indicates changing of the nodes' pressure is uniform and nonlinear due to the nodes' demand and pipes roughness coefficient changes. Nodes' pressure of scenarios S3 and S2 in each fuzzy a-cut have the maximum and minimum values between the four scenarios, respectively. The pressure values of scenarios S1 and S4 are in the range of scenarios S2 and S3. Therefore, pressure values of the S2 and S3 scenarios are considered as the lower and upper limits of the nodes' pressure MF. In scenario S2, the nodes' pressure conditions are critical, so it is called the "critical scenario" in this study.

According to Fig. 10 , in scenario 22 , for fuzzy a-cut less than 0.4 , node No.104 will always face a pressure shortage during the design planning period because the node's available pressure is less than the node's required pressure. In scenarios S1, S3, and S4 for all fuzzy a-cuts, the required pressure and demand of node 
104 will be met. The nodes ' required pressure is supplied in the critical scenario (S2) for fuzzy a-cuts greater than 0.4 .

In node No.63, in critical scenario (S2), only for fuzzy a-cut less than 0.2 , the required pressure demand is not supplied. In the other scenarios, including S1, S3, and S4, the node required pressure is continuously supplied for all fuzzy a-cuts.

\subsection{Uncertainty analysis of the WDN nodes pressure}

Based on the proposed approach, various uncertain scenarios are defined to investigate the pressure situation of nodes after implementing the optimal instructions for the replacement and repair of network pipes. Knowing the status of node pressure requires analysis of node pressure in various uncertain scenarios, which is discussed below.

3.5.1 Scenario S2: Scenario S2 is the critical scenario of the studied WDN. Therefore, first the nodes pressure in the scenario is investigated. Figures 12 to 16 show the nodes pressure of the studied WDN in this scenario.

As Fig. 12 shows, in the S2 scenario and zero fuzzy a-cut, in the first year after the implementation of the optimal instructions, the required pressure of most nodes is not supplied. In this case, the required pressure of only three nodes is supplied. Out of 101 nodes that have pressure deficiency, 22 nodes have negative pressure. Due to the nodes demand increase and also the pipes roughness coefficient decrease in this scenario, the pipes hydraulic head loss increases significantly and as a result the hydraulic grade line located lower than the pipe and leads to negative pressure in some nodes. From the second to the fifth year, the nodes' pressure situation will be better than the first year, so the nodes' average pressure in the second to fifth years is $28.73,18.46$, 21.12, and 18.92 meters, respectively. Jafari (2020) stated that the nodes pressure improvement in the second year is due to the optimal instruction. In the $\mathrm{S} 2$ scenario and lower uncertainty level, i.e., $\alpha=0.2$, despite the nodes' pressure improvement compared to $\alpha=0$, in the first year only eight nodes and the second to fifth years respectively $22,13,21$, and 12 nodes have a pressure higher than the required pressure, and in the remaining nodes there will still be a lack of pressure (Fig. 13).

3.5.2 Scenario S3: In scenario S3, the pipes' longitudinal head loss and the nodes' pressure values will be the minimum and maximum, respectively. In this scenario, all nodes' required pressure and, consequently, demand is supplied during the planning period (Fig. 14).

In this scenario, at the highest uncertainty level of the input parameters, the nodes' average pressures from the first to fifth years are 48.12, 52.48, 51.82, 52.59, and 51.95 meters, respectively. in other alfa-cut, the required pressure of all nodes is supplied.

The occurrence of pressure higher than the maximum allowable pressure in the WDN nodes causes various issues and problems such as pipe bursts and leakage. Therefore, observing the maximum allowable values of the nodes' pressure is essential in the WDN design and operation.

3.5.3 Scenarios S1 and S4: Scenario S1 is a combination of the minimum input variables and scenario S4 is a combination of the maximum input variables. Figures 15 and 16 show the nodes pressure of the studied WDN in scenarios S1 and S4 at the highest input uncertainty level. In scenario S4, in the first year, 45 nodes out of 104 nodes (equivalent to 43\%) have a lower pressure than the required pressure. In the following years, the 
number of nodes with pressure deficiency decreased so that from the second to fifth years, 21, 23, 22, and 23 nodes have pressure deficiency, respectively. In this scenario, nodes pressure redundancy does not occur in the first year, but six nodes have pressure redundancy from the second to fifth years. A study of the higher uncertainty levels shows that the required pressure is supplied to most network nodes (more than $85 \%$ ).

In scenario S1 and in the first year, 35 nodes out of 104 network nodes (equivalent to $33 \%$ ) have a pressure lower than the required pressure. In the following years, the number of nodes with pressure deficiency decreased so that from the second to fifth years, 12,16,13, and 16 nodes have pressure deficiency, respectively. In this scenario, the nodes pressure redundancy does not occur in the first year, but seven nodes have pressure redundancy per year from the second to fifth year.

Based on the above analysis, the nodes pressure deficiency of the studied WDN occurs in different scenarios and under the highest uncertainty level of the nodes' demand and the pipes roughness coefficient. At the highest level of uncertainty, the uncertainty interval of the pipe roughness coefficient and the nodes' demand are equal to $[-20+10]$ and $[-15+20]$ percent of the crisp values, respectively. The mean pressure uncertainty interval of the WDN nodes due to the uncertainty of the pipe roughness coefficient and nodes demand is presented in Table 7.

Table 7

Mean pressure uncertainty interval of nodes in the four scenarios and $\alpha=0$ (\%)

\begin{tabular}{|llllll|}
\hline $\begin{array}{l}\text { Year } \\
\text { Scenarios }\end{array}$ & First & Second & Third & Fourth & Fifth \\
\hline S1 & -9 & -8.4 & -6.2 & -5.6 & -6 \\
\hline S2 & -84 & -54 & -58 & -53 & -58 \\
\hline S3 & 27 & 18 & 19 & 18 & 19 \\
\hline S4 & -13 & -8.4 & -9.1 & -8.3 & -8.9 \\
\hline
\end{tabular}

The negative and positive signs in Table 7 indicate the decrease and increase of the nodes' pressure due to input variables' uncertainty compared to the crisp value. According to this table, in the critical scenario (S2) and the highest uncertainty level, the average pressure uncertainty interval of the WDN nodes is negative and between 53 to $84 \%$. In other words, in this scenario and the highest uncertainty level, the nodes pressure is significantly reduced (more than $50 \%$ ). In the condition the WDN nodes pressure is much less than the minimum allowable pressure, the uncertainty interval of the nodes pressure is unacceptable and will cause many operational problems. In Scenario S3, the average pressure uncertainty interval of the WDN nodes is positive and between $18 \%$ and $27 \%$. Despite the pressure increase, the pressure of different network nodes is still lower than the allowable pressure, so in the scenario and zero fuzzy $\alpha$ - cut, the pressure uncertainty intervals are acceptable. In scenarios S1 and S4, the average interval of node pressure uncertainty is always negative and changes from 5.6 to $13 \%$. With the pressure reduction, the nodes pressure is always higher than the minimum allowable pressure and is acceptable.

\subsection{Uncertainty analysis of WDN reliability}

Page 14/29 
In order to evaluate the WDN hydraulic performance under uncertainty of input parameters, the network reliability index $\left(\mathrm{Re}_{\text {sys }}\right)$ that developed by Jafari 2020 is used. The hydraulic reliability index values of the studied WDN under scenario S2 during the planning period, are presented in Fig. 17.

As shown in Fig. 17, in the critical scenario (S2) and zero fuzzy $\alpha$ - cut, the reliability index is very low and in the range of 0.3 to 0.42 during the planning period because of the pressure deficiency in most of the WDN nodes. Reliability index values fluctuation in the S2 scenario during the planning period is due to the nodes' pressure fluctuations (decreases or increases) in different years. In scenario S3, the reliability index values in the highest uncertainty level are in the range of 0.93 . The high value of the reliability index in this scenario is due to supplying the required pressure of the WDN nodes. In scenarios S1 and S4, the reliability index values are between 0.70 to 0.80 . It is due to the pressure supply of a large number of the WDN nodes. Despite the high uncertainty level of the input variables, the studied WDN performance in these two scenarios is relatively good.

In S2 scenario and $\alpha=0.2$, the reliability index in the first year, is less than 0.50 , which indicates low WDN performance. Failure to supply pressure of most network nodes causes reducing the WDN hydraulic performance (Fig. 18).

The reliability index values at the $\alpha=0.4,0.6$, show that the index values are still about 0.70 to 0.80 in the first year. However, even in the critical scenario, the index values are more than 0.85 , from the second to fifth years, which indicates the acceptable performance of the WDN (Figs. 19 and 20).

Based on the uncertainty interval of the input variables, the uncertainty interval of the reliability index in four scenarios and $\alpha=0$ is presented in Table 8 .

Table 8

Uncertainty interval of reliability index in the four scenarios and $\alpha=0(\%)$

\begin{tabular}{|llllll|}
\hline Year & First & Second & Third & Fourth & Fifth \\
Scenarios & & & & & \\
\hline S1 & -12 & -17 & -14 & -18 & -16 \\
\hline S2 & -64 & -53 & -60 & -52 & -62 \\
\hline S3 & 10 & 3 & 2.6 & -2 & -1.6 \\
\hline S4 & -16 & -22 & -17 & -19 & -17 \\
\hline
\end{tabular}

The negative and positive signs in Table 8 indicate the decrease and increase of the reliability index due to the input variable uncertainty compared to the crisp input variables. In S2 scenario and the highest uncertainty level, a $20 \%$ decrease in pipes roughness coefficient and a $20 \%$ increase in nodes demand, the reliability index uncertainty of the WDN is between $-52 \%$ and $-64 \%$ during the planning period. The crisp value of the reliability index in this scenario is about 0.30 to 0.40 , so with a decrease of 52 to $64 \%$ due to the input's uncertainty, the index values reduce to less than 0.2 , which indicates WDN performance is feeble at the highest uncertainty level. 
In scenario S3 and $\alpha=0$, the uncertainty interval of the WDN reliability index is between -2 to 10 percent. Therefore, considering the crisp index values in scenario S3, the reliability index values are always more than 0.9 .

In Scenario S1 and $\alpha=0$, the reliability index values range from $12-18 \%$ during the planning period. In uncertain conditions, the reliability index values are always more than 0.70 due to the crisp value of this index. In the S4 scenario and $\alpha=0$, the uncertainty of the reliability index values also decreases and is in the acceptable range of $16-22 \%$. The index value in uncertain conditions is always more than 0.68 . At higher uncertainty levels, except in the first year, the reliability index uncertainties are always less than $15 \%$.

\subsection{Investigation of computational features of the proposed approach}

In addition to uncertainty analyses of the optimal instructions as one of the innovations of this research, reduction in the calculations volume and run time in analyzing the uncertainty of optimal instructions is another innovation of this research. Based on fuzzy alfa-cut method and by applying five alfa-cuts for each node and pipe in four scenarios, a total of 20 simulations to calculate the pressure values of network nodes are required. If the optimization method is used to find the limit values of network nodes' pressure, the number of simulation iterations increases significantly (Table 4).

Table 4

Computation specifications of the proposed uncertainty analysis approach

\begin{tabular}{|llll|}
\hline Method & Number of iterations & Run time (hr) & Computer properties \\
\hline Optimization & $6 \times 10^{5}$ & 834 & CPU-8cor, RAM-16Gb and HDD-100Gb \\
\hline Simulation & 20 & 0.027 & CPU-2cor, RAM-8Gb and HDD-50Gb \\
\hline
\end{tabular}

As shown in Table 4, using proposed approach reduces the volume of calculations and run time in the uncertainty analysis of optimal instructions and ease of handling the uncertainty of input variables.

\section{Conclusion}

In this research, a fuzzy method is developed for uncertainty analysis of optimal WDN pipes repair and replacement instruction. Optimal instruction of Gorgan's WDN provided by Jafari (2020) is considered a case study. Pipes' roughness coefficient and nodes' demand are considered WDN uncertain input variables, and the nodes' pressure during the planning period (5 years) is considered as uncertain output variable. The fuzzy a cut method used to handle and quantify the uncertainty of the variables. A triangular MF selected for the uncertain input variables, based on the variable's nature and recorded data. The extreme values of the input variables in each fuzzy a-cut are derived from the variable's MF. In order to investigate the simultaneous effect of input uncertainty variables, the extreme values combinations of two uncertain input variables considered as four different scenarios.

Changes in node pressure are uniform versus pipe roughness coefficient and node demand. Therefore, the WDN hydraulic simulation is used to calculate the extreme values of nodes' pressures based on fuzzy MF of 
input variables.

In scenario S1 and fuzzy a-cut less than 0.2 , the required pressure of significant parts of the network nodes is supplied, except in the first year. Therefore, the WDN reliability index is always more than 0.8. The MF of nodes' pressure show that the node pressure values in scenario $\$ 2$ always are the minimum values, so this scenario is called the critical scenario. In this scenario and the highest uncertainty level, about $22 \%$ of the WDN nodes have negative pressure, and $3 \%$ have pressure deficit in the first year. In the subsequent years, pressure deficiency is observed in most WDN nodes so that the required pressure of only about $8 \%$ of the nodes is supplied.

Therefore, the WDN reliability index is very low and between 0.3 to 0.4 . By reducing the uncertainty level to a-cut equal 0.2 , most nodes still have pressure deficiency, and the WDN reliability index is less than 0.7. Nodes' pressure values in scenario S3 constitute the upper limit of nodes' pressure in the fuzzy MF. In the scenario, the required pressure of all nodes is always supplied even in the highest uncertainty level of the input variables, during the project planning period. Therefore, the WDN reliability index values are always more than 0.93 . Study of the uncertainty interval of the nodes pressure and the reliability index show that only in the critical scenario (S2) and the highest uncertainty level of the input variables, uncertainty interval of the nodes pressure and the reliability index is very high and always more than 0.5 .

Using a combination of fuzzy alfa-cut method and hydraulic simulation of the network facilitates the quantification of input variability uncertainty and significantly reduces the volume of calculations and run time in the uncertainty analysis of optimal instructions.

Generally, the fuzzy uncertainty analysis of the optimal instruction of the studied WDN shows that:

- The studied WDN does not have acceptable performance only in scenario S2 and the highest uncertainty level of the input variables, so proper operation management is necessary. In other scenarios and uncertainty levels, the hydraulic performance of the WDN is acceptable.

- Performance of the studied WDN under the input variables uncertainty can be analyzed with acceptable accuracy and low computational volume using the proposed method. Then the necessary decisions can be made to face the consequences of the uncertain input values.

- Using a combination of fuzzy and simulation approaches, the speed of model execution to analyze the uncertainty of the optimal instructions are significantly reduced.

- Using the fuzzy method to consider the input variables uncertainty in the optimization process of the pipes repair and replacement instructions in future studies can provide flexible instructions so that the WDN has an acceptable performance under uncertainty input variables.

\section{Declarations}

Consent to Participate Not Applicable

Consent to Publish Not Applicable

Authors Contributions S. M. Jafari: Conceptualization, Data acquisition, Writing- Original draft preparation, Editing of manuscript; A. R. Zahiri: Conceptualization, Visualization, Supervision; O. Bozorg Hadad: 
Conceptualization, Supervision, Visualization; Mahmoud Mohammad Rezapour Tabari: Conceptualization, Supervision, Methodology, Visualization, Editing of manuscript

Funding Not Applicable

Competing Interests The authors declare that they have no known competing financial interests or personal relationships that could have appeared to influence the work reported in this paper.

Availability of data and materials Data and material would be made available on request.

\section{References}

1. Abeb AJ, Guinot V, Solomatine DP (2000) Fuzzy alpha-cut vs. Monte Carlo techniques in assessing uncertainty in model parameters. InProceedings of 4th international conference on hydroinformatics, Cedar Rapids.

2. Baños R, Reca J, Martínez J, Gil C, Márquez AL (2011) Resilience indexes for water distribution network design: a performance analysis under demand uncertainty.Water resources management25(10):2351-2366

3. Branisavljevic N, Ivetic M (2006) Fuzzy approach in the uncertainty analysis of the water distribution network of Becej. Civ. Eng. Environ. Syst. 23(3): 221-236

4. Dini M, Tabesh M (2018) ANew Reliability Index for Evaluating the Performance of Water Distribution Network.Journal of Water and Wastewater29(3): 1-16 (In Persian).

5. Donger SR, Gupta R(2017) Optimal design of water distribution network under hydraulic uncertainties. ASCE-ASME J. Risk Uncertainty Eng. Syst. 3(3): 1-11

6. DridiL, Parizeau M, Mailhot A, Villeneuve JP (2008) Using evolutionary optimization techniques for scheduling water pipe renewal considering a short planning horizon.Computer-Aided Civil and Infrastructure Engineering23(8): 625-635

7. Farmani R, Savic DA, Walters GA (2005a) Evolutionary multi-objective optimization in water distribution network design. Engi. Opti. 37(2): 167-183

8. Farmani R, Savic DA, Walters GA (2005b) Fuzzy rules for hydraulic reliability-based design and operation of water distribution systems. In: Proc., Impacts of Global Clim. Change, 1-9

9. Geranmehr M, Asghari K, Chamani MR (2019) Uncertainty analysis of water distribution networks using type-2 fuzzy sets and parallel genetic algorithm.Urban Water Journal16(3): 193-204

10. Gupta R, Bhave PR (2007) Fuzzy parameters in pipe network analysis. Civ. Eng. Environ. Syst. 24(1): 3354

11. Haghighi A,AsI AZ (2014) Uncertainty analysis of water supply networks using the fuzzy set theory and NSGA-II. Eng. Appl. Artif. Intell. 32: 270-282

12. Hwang, H., Lansey, K. and Jung, D., (2018). Accuracy of first-order second-moment approximation for uncertainty analysis of water distribution systems. Journal of Water Resources Planning and Management, 144(2), p.04017087.

13. Ivetić M (1996) Control Valves-Principles of Operation. InWater Supply Systems, Springer, Berlin, Heidelberg, 145-159 
14. Jafari SM, Zahiri AR, Bozorg-HaddadO, Tabari MMR (2020) New Approach for Prediction of Water Distribution Network Pipes Failure Based on an Intelligent Hybrid Model (Case Study: Gorgan Water Distribution Network), Journal of water and soil conservation 27(5): 149-166 (in persion).

15. Jafari SM (2020) Multi-objective optimization of water distribution systems under demand and roughness uncertainties and pipe breakages, Ph.D. Thesis, Gorgan university of Agriculture science and natural resources.

16. Jafari SM, Zahiri AR, Hadad OB, Tabari MMR (2021) A hybrid of six soft models based on ANFIS for pipe failure rate forecasting and uncertainty analysis: a case study of Gorgan city water distribution network.Soft Computing25(11): 7459-7478

17. Kapelan Z, Savic DA, Walters GA (2005) Decision-support tools for sustainable urban development. InProceedings of the Institution of Civil Engineers-Engineering Sustainability 158(3): 135-142

18. Liu H, Savić DA, Kapelan Z, Creaco E, Yuan Y (2017) Reliability surrogate measures for water distribution system design: Comparative analysis.Journal of Water Resources Planning and Management143(2): 04016072

19. Moosavian N, Lence BJ,(2018) Approximation of fuzzy membership functions in water distribution network analysis. J. Hydraul. Eng. 144 (7): 04018039

20. Revelli R, Ridolfi L (2002) Fuzzy approach for analysis of pipe networks. J. Hydraul. Eng. 128(1): 93-101

21. Sabzkouhi AM, Haghighi A (2016) Uncertainty analysis of pipe-network hydraulics using a many-objective particle swarm optimization. J. Hydraul. Eng. 142(9): 1-12

22. ScholtenL, Scheidegger A, Reichert P, Mauer M, Lienert J (2014) Strategic rehabilitation planning of piped water networks using multi-criteria decision analysis. Water Research 49: 124-143

23. Seifollahi-Aghmiuni S, Haddad OB, Omid MH, Mariño MA, (2013) Effects of pipe roughness uncertainty on water distribution network performance during its operational period. Water resources management27(5): 1581-1599

24. Shafiqul Islam M, Sadiq R, Rodriguez MJ, Najjaran H, Hoorfar M (2014) Reliability assessment for water supply systems under uncertainties.Journal of Water Resources Planning and Management140(4): 468479

25. Sharp WW, Walski TM (1988) Predicting internal roughness in water mains.Journal-American Water Works Association80(11): 34-40

26. Shibu A, Reddy MJ (2011) Uncertainty analysis of water distribution networks by fuzzy-cross entropy approach. World Acad. Sci., Eng. Technol. 59: 724-731

27. Shibu A, Reddy MJ (2012) Least cost design of water distribution network under demand uncertainty by fuzzy -cross entropy method. J. Environ. Res. Dev. 6 (3A): 853-862

28. Taebi A, Chamani MR (2005) Urban water distribution networks.publication center of Isfahan Industrial University, Isfahan (In Persian)

29. Tolson, B.A., Maier, H.R., Simpson, A.R. and Lence, B.J., (2004). Genetic algorithms for reliability-based optimization of water distribution systems. Journal of water resources planning and management, 130(1), pp.63-72. 
30. Wang Q, Guidolin M, Savic D, Kapelan Z (2015) Two-objective design of benchmark problems of a water distribution system via MOEAs: Towards the best-known approximation of the true Pareto front.Journal of Water Resources Planning and Management141(3): 04014060

31. Zadeh, L.A., 1965. Zadeh, Fzzy sets. J. Klir and B. Yuan, Editors, Fuzzy sets, fuzzy logic, and fuzzy systems, pp.19-34.

\section{Figures}

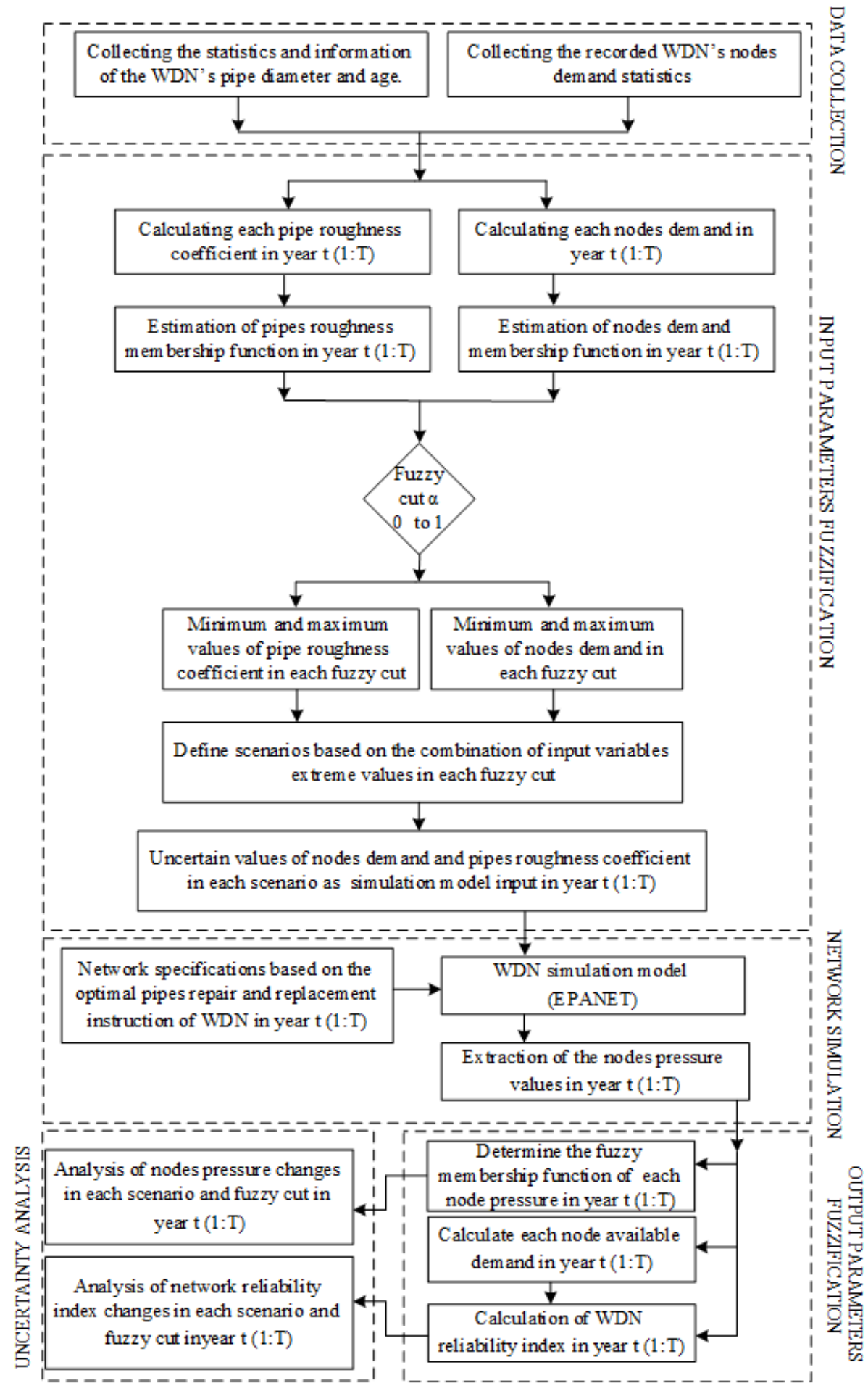

Figure 1

Page 20/29 
Structure of the uncertainty analysis approach for the optimal instruction

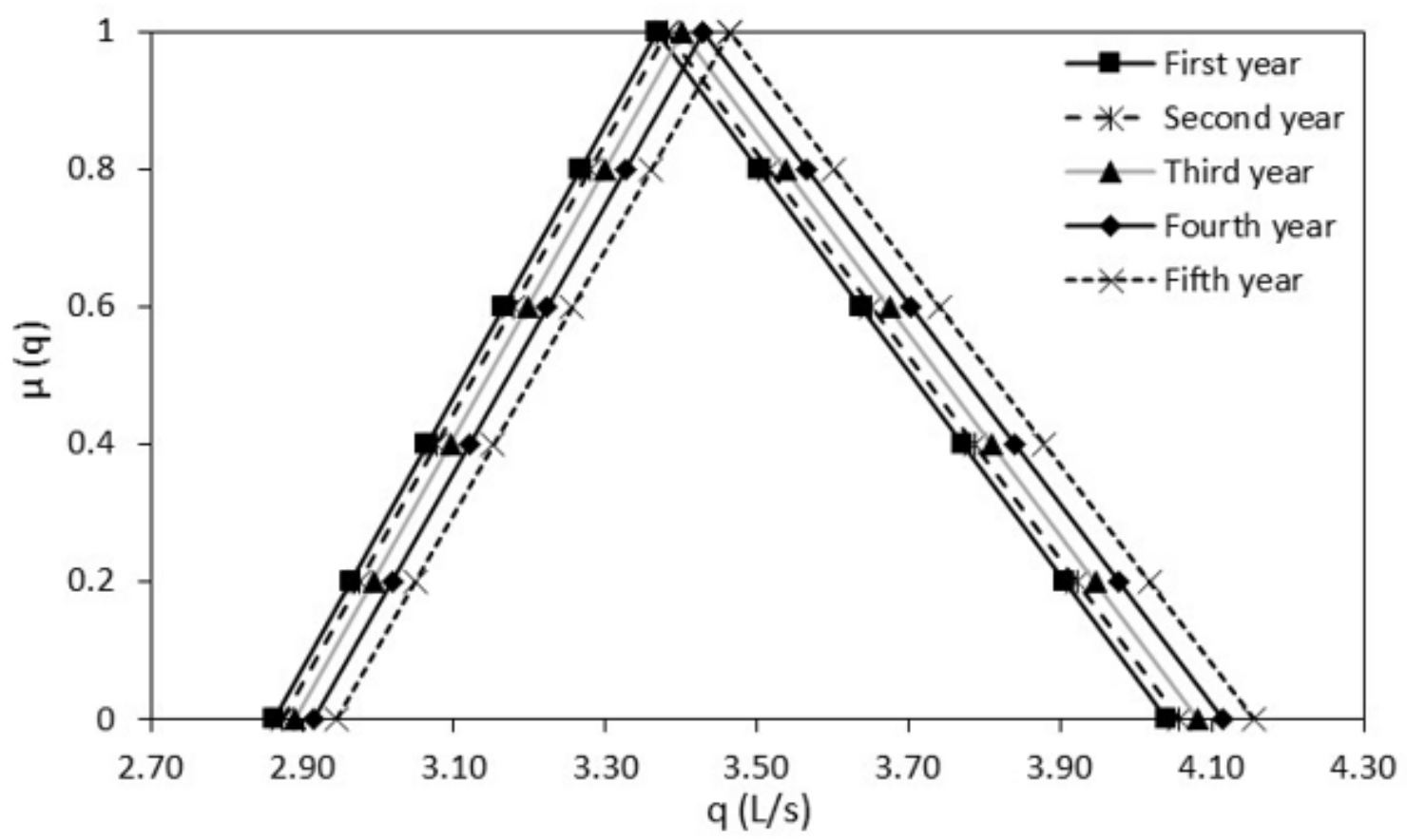

Figure 2

MF of demand No. 54

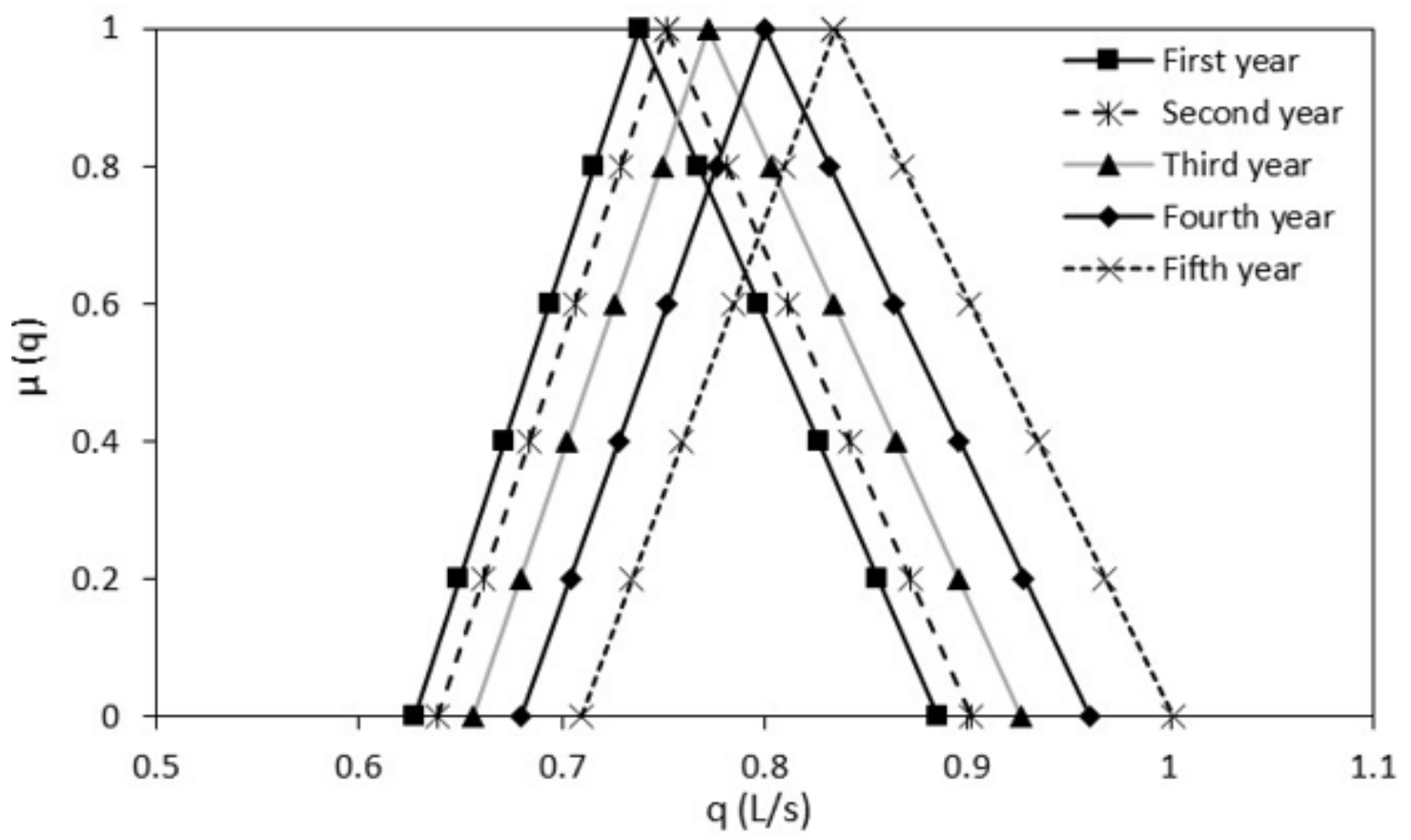

Figure 3

MF of demand No. 41 


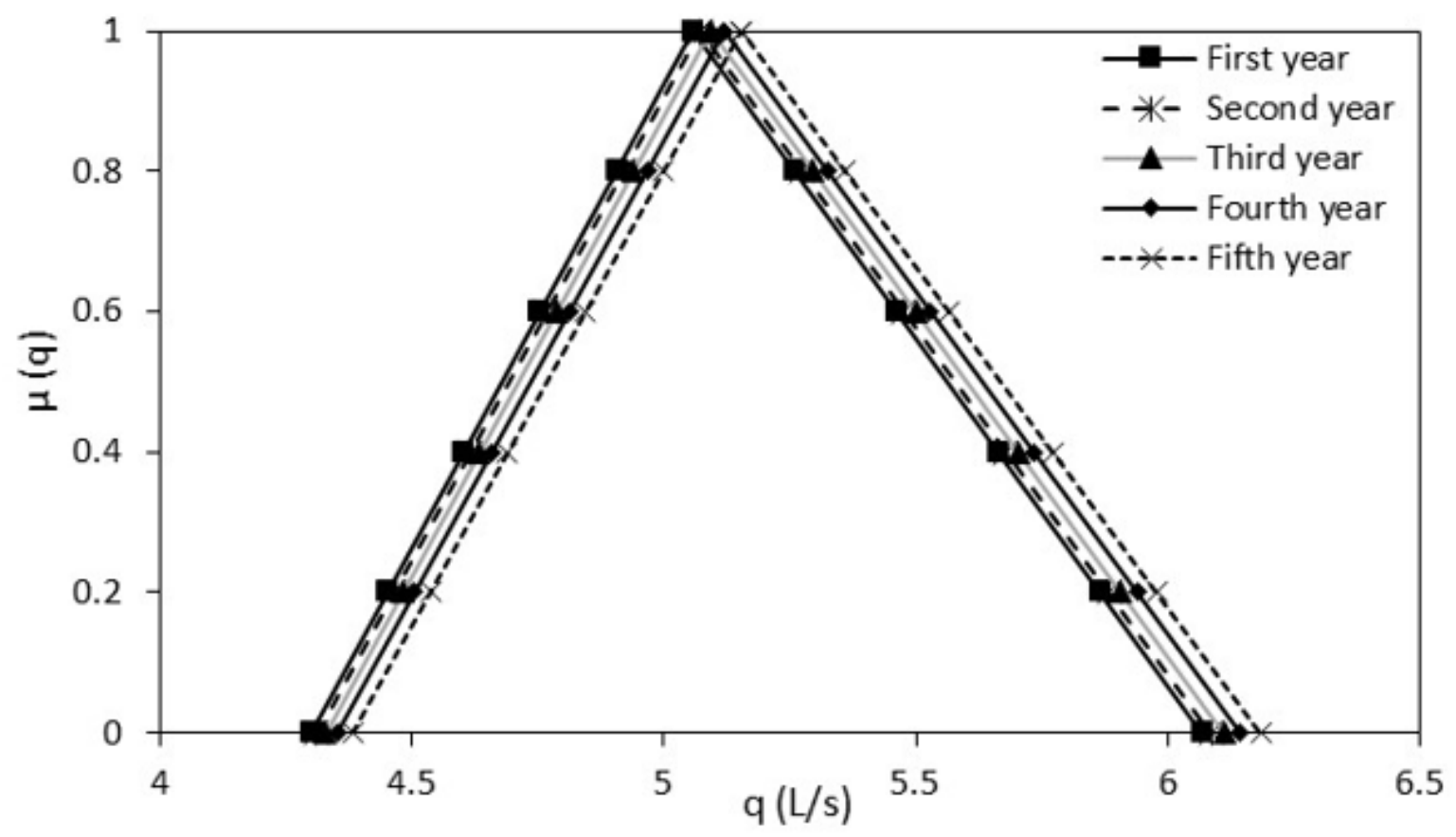

Figure 4

MF of demand No. 104

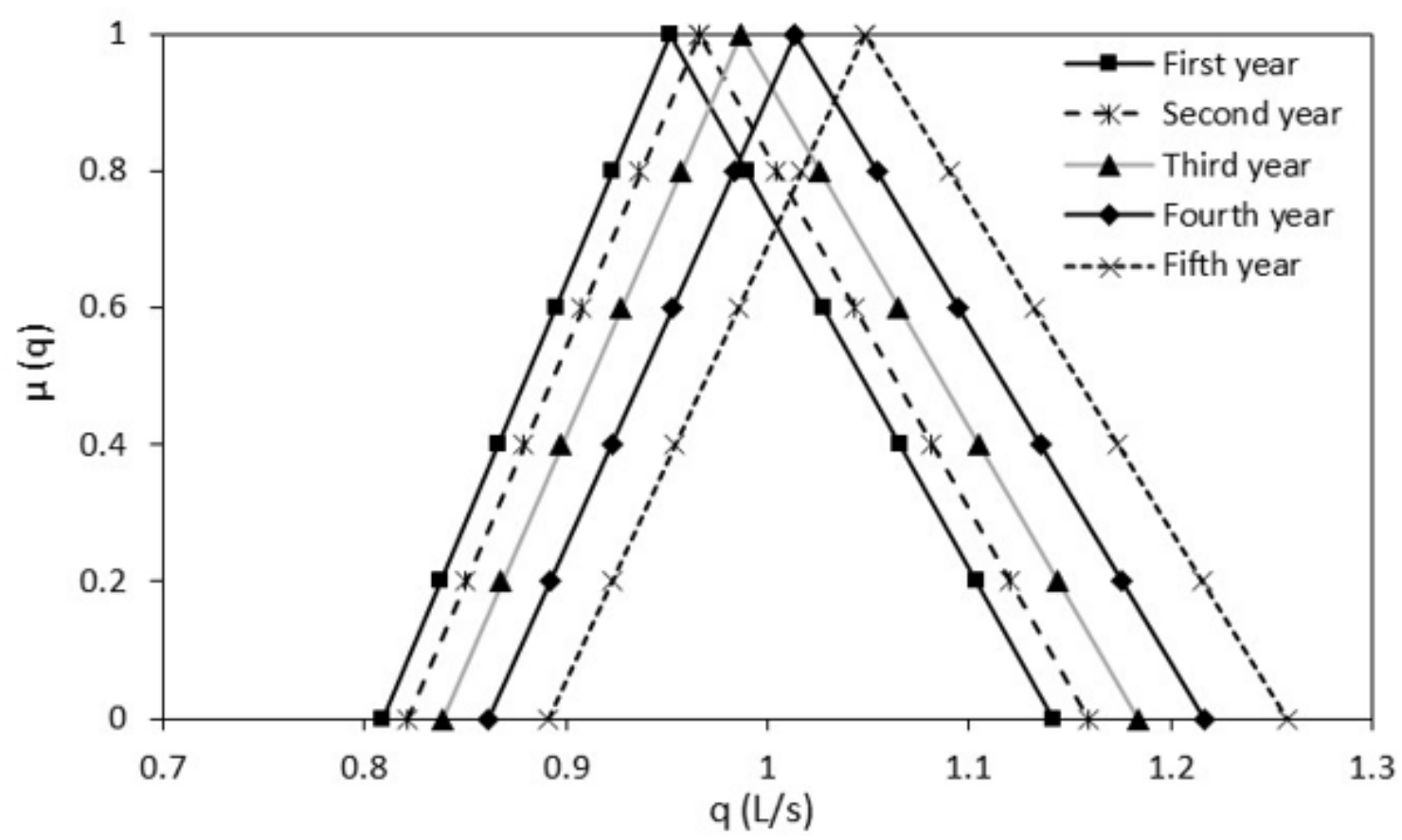

Figure 5

MF of demand No. 63 


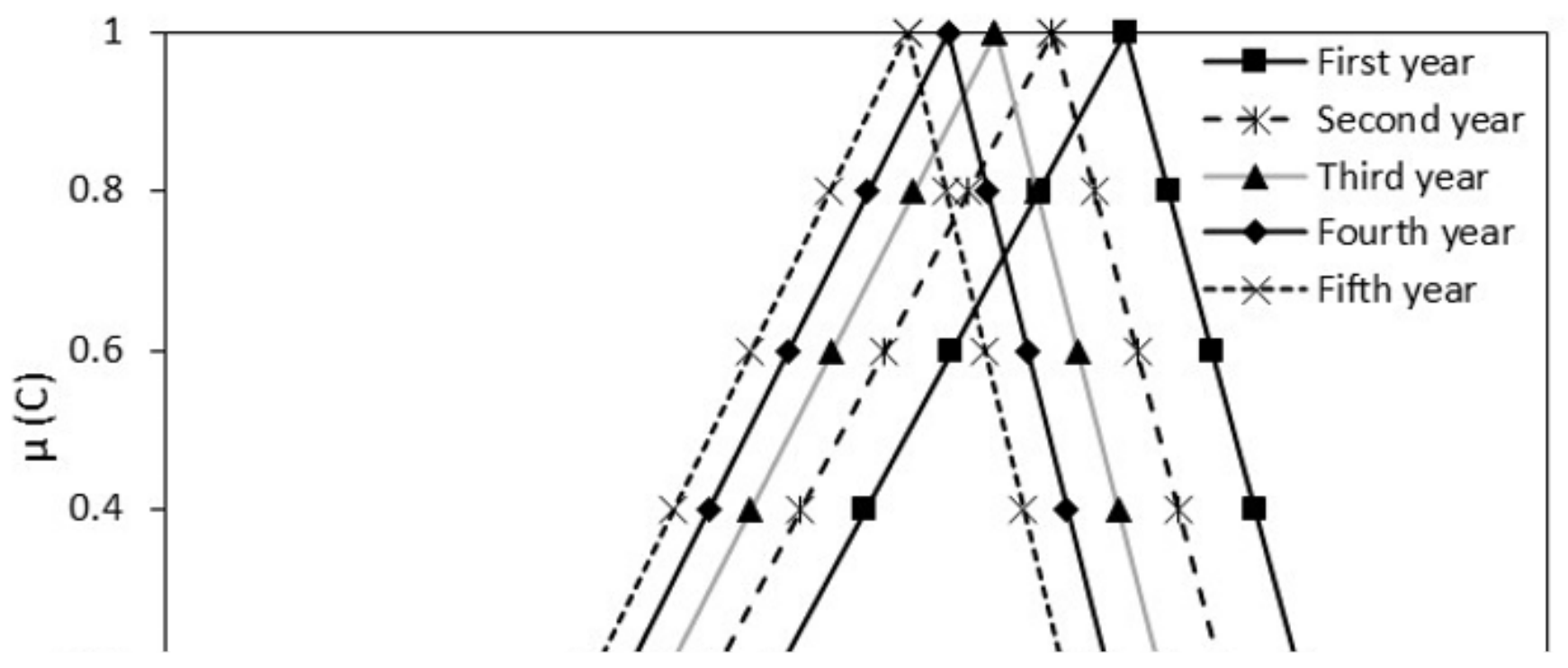

Figure 6

Pipe roughness coefficient MF of pipe No. 16

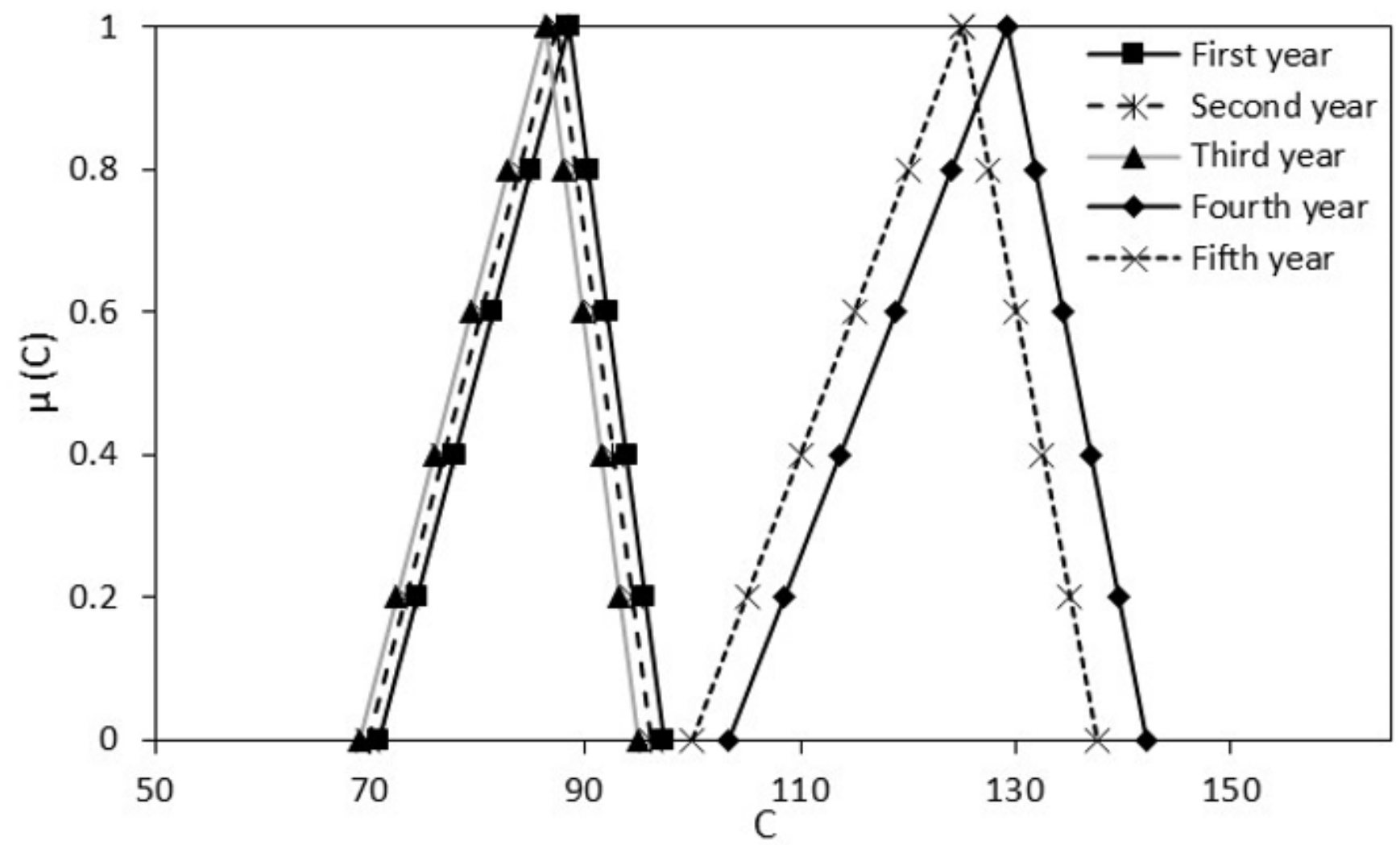


Figure 7

Pipe roughness coefficient MF of pipe No. 60

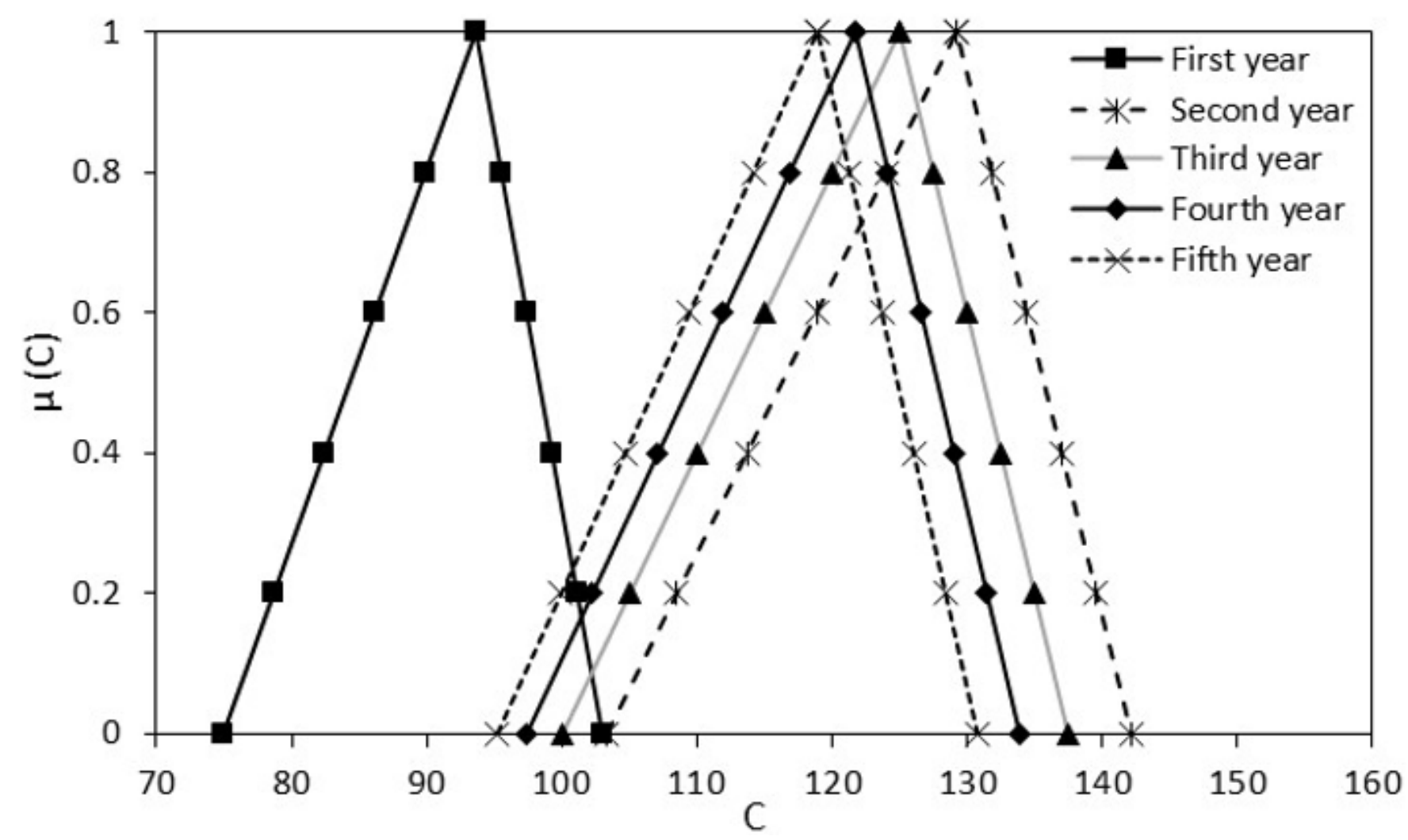

Figure 8

Pipe roughness coefficient MF of pipe No. 74

Figure 9

Pipe roughness coefficient MF of pipe No. 97 

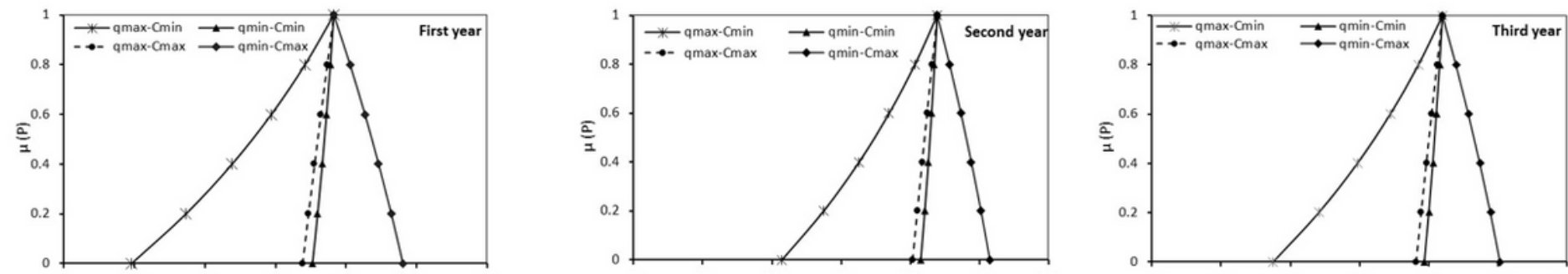

\section{Figure 10}

Fuzzy MF of pressure node No.104 for four scenarios during planning period

\section{Figure 11}

Fuzzy MF of pressure node No.63 for four scenarios during planning period 

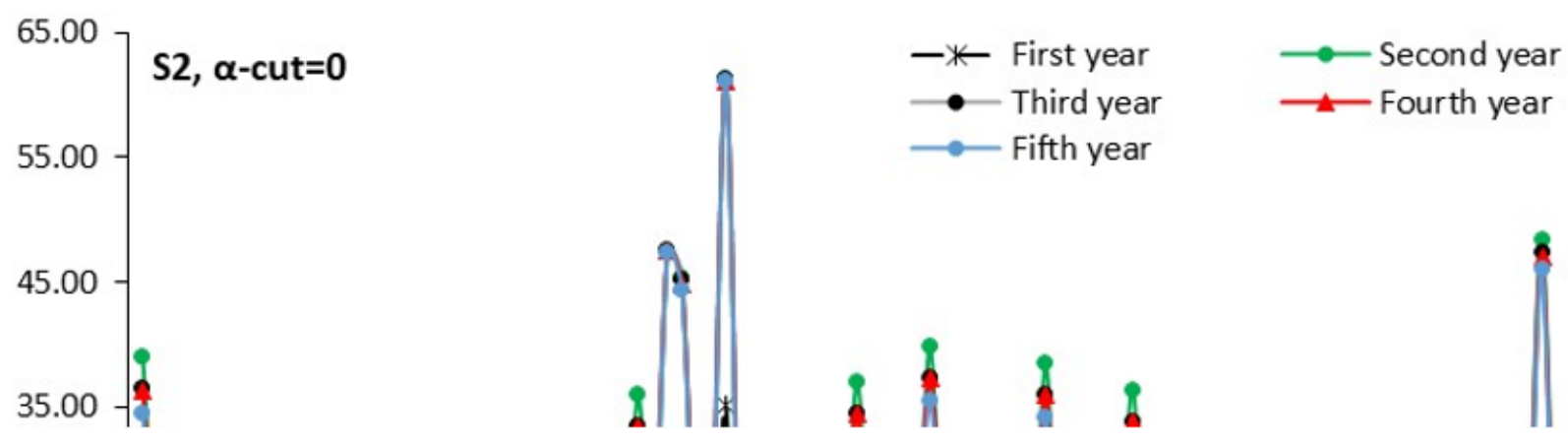

\section{Figure 12}

Node's pressure of the studied WDN in the $S 2$ scenario and $a=0$

\section{Figure 13}

Node's pressure of the studied WDN in the $S 2$ scenario and $a=0.2$

\section{Figure 14}

Node's pressure of the studied WDN in the S3 scenario and $a=0$ 

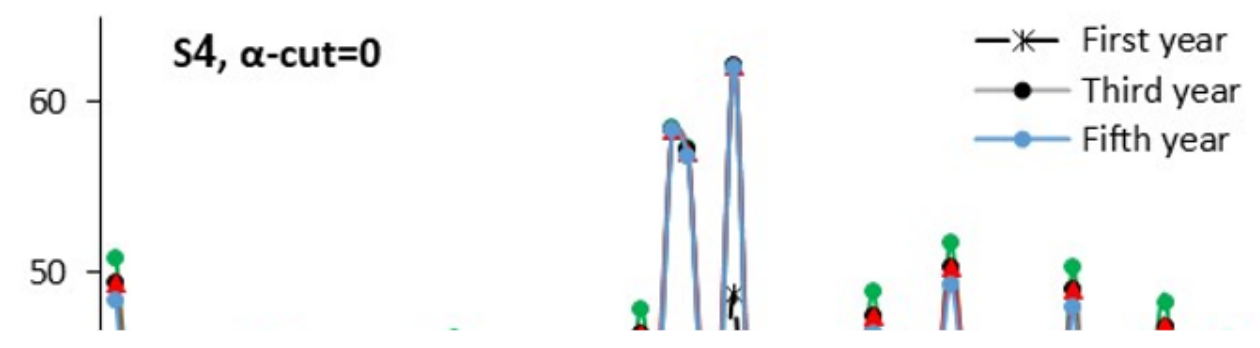
$\longrightarrow$ Second year
$\longrightarrow$ Fourth year

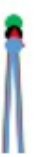

\section{Figure 15}

Node's pressure of the studied WDN in the S4 scenario and $a=0$
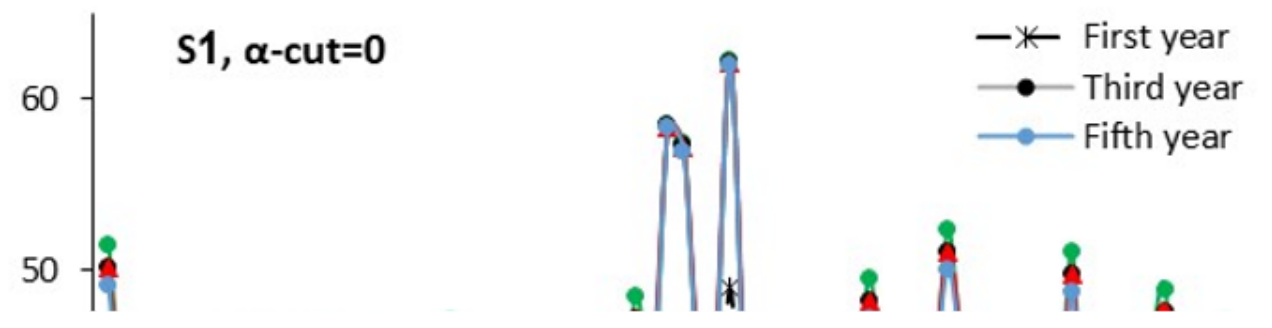
$\longrightarrow$ Second year
$\longrightarrow$ Fourth year

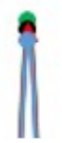


Figure 16

Node's pressure of the studied WDN in the S1 scenario and $a=0$

Figure 17

Reliability index in the four Scenario and $a=0$

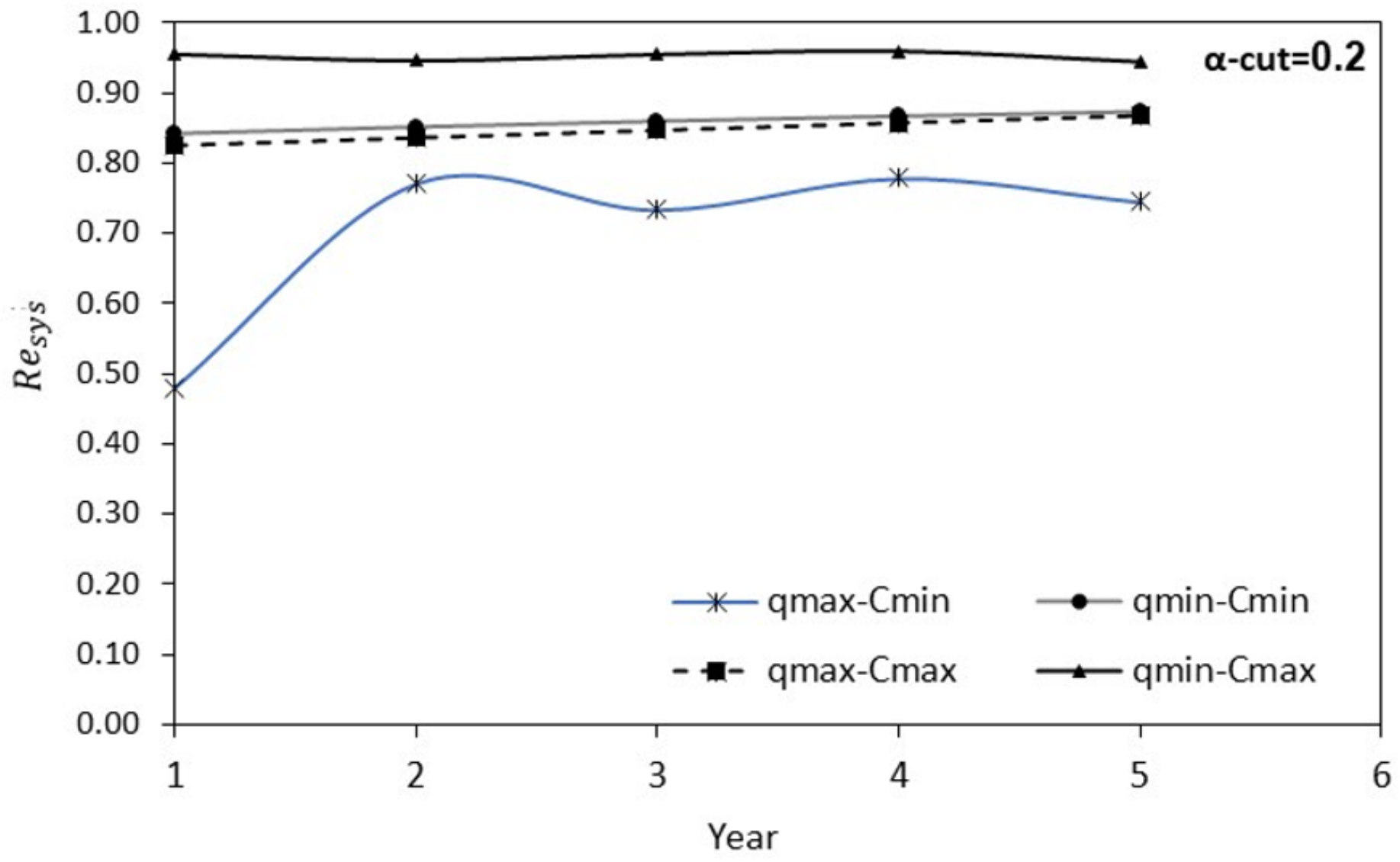

Figure 18

Reliability index in the four Scenario and $a=0.2$

Figure 19

Reliability index in the four Scenario and $a=0.4$ 


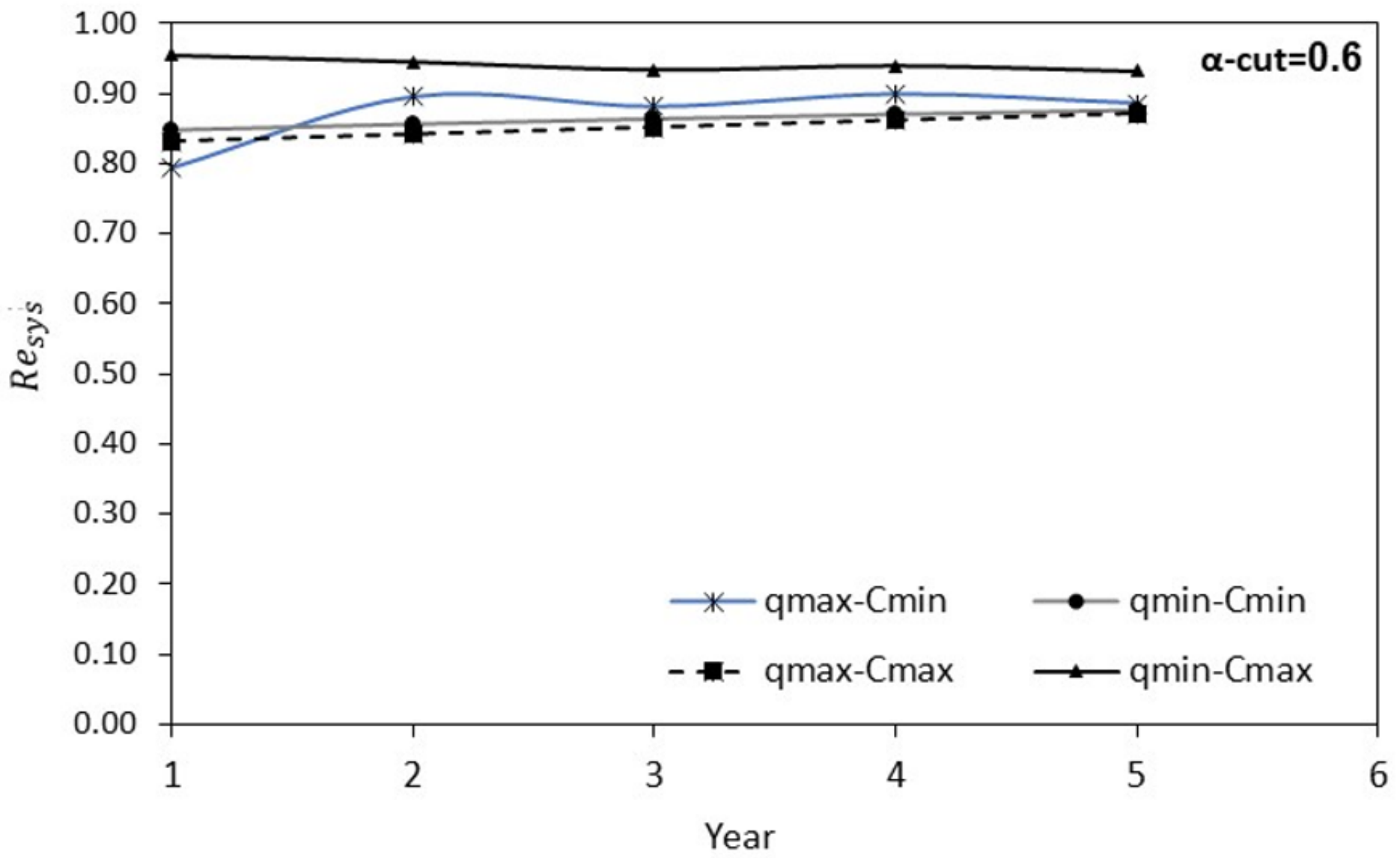

Figure 20

Reliability index in the four Scenario and $a=0.6$ 